\title{
Article
}

\section{Young Swimmers' Middle-Distance Performance Variation within a Training Season}

\author{
Sara Ferreira ${ }^{1,2}$, Diogo Duarte Carvalho ${ }^{1,2}$, Ricardo Cardoso ${ }^{1,2}\left(\right.$, Manoel Rios ${ }^{1,2} \oplus$, Susana Soares ${ }^{1,2} \mathbb{C}^{(}$, \\ Argyris Toubekis ${ }^{3}$ (D) and Ricardo J. Fernandes ${ }^{1,2, *(D)}$ \\ 1 Centre of Research, Education, Innovation and Intervention in Sport, Faculty of Sport, University of Porto, \\ 4200-450 Porto, Portugal; sara_ferreira_1120@hotmail.com (S.F.); diogoduarte_03@hotmail.com (D.D.C.); \\ ricardocardoso.coach@gmail.com (R.C.); manoel.rios@hotmail.com (M.R.); susana@fade.up.pt (S.S.) \\ 2 Porto Biomechanics Laboratory, University of Porto, 4200-450 Porto, Portugal \\ 3 School of Physical Education \& Sport Science, National and Kapodistrian University of Athens, \\ 17233 Athens, Greece; atoubekis@phed.uoa.gr \\ * Correspondence: ricfer@fade.up.pt
}

Citation: Ferreira, S.; Carvalho, D.D.; Cardoso, R.; Rios, M.; Soares, S.; Toubekis, A.; Fernandes, R.J. Young Swimmers' Middle-Distance

Performance Variation within a Training Season. Int. J. Environ. Res. Public Health 2021, 18, 1010. https:// doi.org/10.3390/ijerph18031010

Received: 22 December 2020

Accepted: 20 January 2021

Published: 24 January 202

Publisher's Note: MDPI stays neutral with regard to jurisdictional claims in published maps and institutional affiliations.

Copyright: () 2021 by the authors. Licensee MDPI, Basel, Switzerland. This article is an open access article distributed under the terms and conditions of the Creative Commons Attribution (CC BY) license (https:// creativecommons.org/licenses/by/ $4.0 /)$

\begin{abstract}
The current study aimed to longitudinally evaluate anthropometric, physiological, and biomechanical variables related to middle-distance performance during a 45-week swimming training season. Thirty-four swimmers (age: $12.07 \pm 1.14$ years) performed a maximum of $400 \mathrm{~m}$ front crawl at the beginning (T1) and finish of the first macrocycle (T2, 15 weeks) and the finish of the second (T3, 18 weeks) and third macrocycles (T4, 12 weeks). Time-related variables, stroke rate (SR), stroke length (SL), and stroke index (SI) were recorded during the test, and blood lactate ([La]) and glucose ([Glu]) concentrations were measured post-exercise. The time of the $400 \mathrm{~m}$ effort decreased after each macrocycle (T2 vs. T1, $7.8 \pm 5.6 \%$; T3 vs. T2, $3.7 \pm 3.1 \%$; T4 vs. T3, $3.8 \pm 3.4 \%$; $p<0.01$ ). Four hundred meter speed changes between $\mathrm{T} 1$ and $\mathrm{T} 2$ were positively related to variations in [La], [Glu], SL, and SI $(r=0.36-0.60, p<0.05)$. Changes between T2 and T3 were related to SI only $(r=0.5$, $p<0.05)$, and modifications between T3 and T4 were associated with SL and SI variations ( $r=0.34$ and $0.65, p<0.05)$. These results indicate that a well-structured year plan including three macrocycles leads to a significant age-group swimming performance improvement, mostly connected with an increase in technical proficiency.
\end{abstract}

Keywords: macrocycle; swimming; lactate; glucose; technique

\section{Introduction}

Swimmers are involved in training and competition at very young ages [1,2], and appropriate training planning, as well as regular testing, should be applied within a training season $[3,4]$. Such an approach aims to guide the development of energetic and biomechanical attributes, leading to improved physical conditioning, skill acquisition, and performance enhancement $[5,6]$. Short, medium, or long training planning should consider the characteristics and specific needs of young swimmers and apply proper periodization. As such, a year plan is divided into shorter periods, normally using one of three periodization designs, including one, two, or three macrocycles. Regarding the threemacrocycle periodization model (each ending with a main competition), the transition period is aligned with school holidays [7]. Due to the connection with the school activities calendar, this specific periodization is likely one of the best suited for young swimmers [8].

To achieve the optimal performance in main competitions, the training load needs to be gradual and specific. It is expected that swimmers improve their performance after each training season by $1 \%$ in the elite level [9] and by up to $10 \%$ in younger swimmers due to growth and performance level [10]. Specialization in young swimmers may occur between 11 and 13 years and 13 and 15 years for girls and boys, respectively [11]. Unfortunately, due to scarce research on the topic, there are limited specific directions on training 
periodization of children and young swimmers. Moreover, during childhood and youth, the progression of maturation affects performance and influences not only physiological variables (e.g., cardiovascular adaptations $[8,12]$ ) but also biomechanical variables (e.g., stroke rate, stroke length, and stroke index (SR, SL, and SI, respectively)) [13,14]. Although cross-sectional studies have focused on the importance of anthropometric, physiological, and biomechanical variables in young swimmers' performance [14-16], few longitudinal studies are directed toward evaluating physiological and biomechanical changes in young swimmers. Even so, some studies have applied interventions over a macrocycle $[3,10,17]$ or a training season $[8,15]$, relating anthropometric, physiological, and biomechanical changes to swimming performance.

For facilitating training periodization, planning, and evaluation of physiological and biomechanical changes over a macrocycle [9] (or repeated macrocycles), valid testing is a prerequisite. In this context, the $400 \mathrm{~m}$ maximum effort has been suggested for testing young swimmers, getting attention in swimming research $[4,8,10]$ since it is regularly used to evaluate the aerobic power of swimmers $[10,18,19]$. Moreover, training control is a primordial task of the coach when the aim is to improve performance in the main competitions $[20,21]$. Appropriate testing, particularly focusing on physiological (e.g., blood lactate concentrations and oxygen uptake) and biomechanical (kinetics and kinematics of the upper and lower limbs' actions) evaluations, helps understand the effect of the training volume and intensity on competitive performance [3,16,22-24]. The purpose of the current study was to describe the evolution of middle-distance swimming performance along with physiological and biomechanical changes in young swimmers during a training season including three macrocycles. We hypothesized that changes in physiological and biomechanical variables are directly related to improved performance during the training season.

\section{Materials and Methods}

Thirty-four competitive swimmers (10 girls and 24 boys) aged between 9 and 14 years, with $\geq$ four land and in-water training sessions per week, participated in the current study. Swimmers with $\leq$ one year of competitive experience were not included. The main characteristics of the participants, including chronological age and maturation stage (verified by a valid and reliable self-assessment of secondary sexual characteristics; [25]), are presented in Table 1.

Table 1. Anthropometric characteristics of the young swimmers engaged in the current study.

\begin{tabular}{cccc}
\hline Variables & Boys $(\boldsymbol{n}=\mathbf{2 4})$ & Girls $(\boldsymbol{n}=\mathbf{1 0})$ & Total Sample $(\boldsymbol{n}=\mathbf{3 4})$ \\
\hline Chronological age (years) & $12.51 \pm 0.99$ & $11.24 \pm 0.88$ & $12.07 \pm 1.14$ \\
Body mass (kg) & $45.90 \pm 9.54$ & $44.26 \pm 8.76$ & $45.42 \pm 9.22$ \\
Stature (m) & $1.56 \pm 0.11$ & $1.52 \pm 0.07$ & $1.55 \pm 0.10$ \\
Tanner stage & $2.94 \pm 1.04$ & $3.05 \pm 1.10$ & $2.97 \pm 1.05$ \\
\hline
\end{tabular}

The swimmers were tested at four moments of the training season: at the beginning (T1) and finish (T2) of the first macrocycle and at the finish of the second (T3) and third (T4) macrocycles. The duration of the first, second, and third macrocycles was 15, 18, and 12 weeks, respectively. The closing of each macrocycle coincided with the important competitions of the season. The training content of each macrocycle is demonstrated in Table 2. At each testing moment, the swimmers were asked to perform a maximum of $400 \mathrm{~m}$ front crawl effort, with the performance time in each $100 \mathrm{~m}$ split and total $400 \mathrm{~m}$ time being recorded by qualified timekeepers (Seiko, Tokyo, Japan). 
Table 2. Swimming training content, volume, and frequency per macrocycle along a young swimmer's training season.

\begin{tabular}{cccc}
\hline Training Type & 1st Macrocycle & 2nd Macrocycle & 3rd Macrocycle \\
\hline Aerobic training (\%) & 91 & 89 & 85 \\
Anaerobic training (\%) & 9 & 11 & 15 \\
Technical training (\%) & 28 & 16 & 14 \\
Conditional training (\%) & 72 & 84 & 86 \\
Distance per week (m) & $19,708 \pm 4207$ & $16,577 \pm 5655$ & $15,933 \pm 5496$ \\
Training sessions per week & $5.83 \pm 0.56$ & $5.80 \pm 0.63$ & $5.82 \pm 0.58$ \\
\hline
\end{tabular}

The heart rate (HR) was recorded using telemetry (Polar Electro, Kempele, Finland) during the recovery period immediately after the $400 \mathrm{~m}$ front crawl effort (at 10, 30, 60, and 120 s). Lactate ([La]; Lactate Pro, Arkay, Inc., Kyoto, Japan) and glucose ([Glu]) concentrations (GlucocardTM, A. Menarini, Paço de Arcos, Portugal) were measured during the third minute of recovery using two capillary blood samples from the swimmer's finger. The rating of perceived exertion (RPE) was recorded at the end of the $400 \mathrm{~m}$ effort on a 20-point scale. To analyze biomechanical variables, a video recorder (HDR-CX160E $60 \mathrm{~Hz}$, Sony, Tokyo, Japan) was placed strategically (above the water and perpendicular to the swimmer direction at a $10 \mathrm{~m}$ distance from the swimming pool). The SR was calculated in the last $25 \mathrm{~m}$ of each $100 \mathrm{~m}$ split by the time taken to complete three consecutive upperlimb cycles (Kinovea software 8.15, Bordeaux, France). The SR assessment was repeated two times (and used the mean value) for assuring reliability. The stroke length (SL) was assessed by the quotient of mean speed with the mean SR [17], and the SI was calculated as the product of the mean SL and the $400 \mathrm{~m}$ mean speed [17]. The diet was controlled by asking swimmers' parents to maintain a similar nutritional content the day before each testing session.

\section{Statistical Analysis}

Normal distribution was tested using the Kolmogorov-Smirnov test, and sphericity was verified using the Mauchly test. When the assumption of sphericity was not met, the significance of $F$-ratios was adjusted according to the Greenhouse-Geisser procedures. To compare the physiological and biomechanical variables, we used a repeated-measures one-way analysis of variance (ANOVA). Furthermore, to compare HR recovery (four testing moments $\times$ four points of recovery) and changes in swimming time, SR, SL, and $\mathrm{SI}$ in each $100 \mathrm{~m}$ lap of the $400 \mathrm{~m}$ test, we used the two-way repeated-measures ANOVA. Analysis of covariance was applied using the maturation stage and body mass index as covariates. A Tukey honest significant difference post-hoc test was used to compare means when significant $F$-ratios were found. Cohen's effect size $(d)$ was calculated as the mean differences divided by the pooled standard deviation and characterized as small $(<0.20)$, medium $(0.2-0.8)$, and large $(>0.8)$ [26]. The $95 \%$ confidence intervals $(95 \% \mathrm{CI})$ were also calculated. To analyze relations between variables, we used the Pearson correlation coefficient. The data were shown as mean \pm standard deviation, and statistical significance was set at $p<0.05$.

\section{Results}

\subsection{Changes in $400 \mathrm{~m}$ Time}

Since no interaction of sex and performance time changes observed between macrocycles $\left(\mathrm{F}_{3.96}=0.105, p=0.96\right)$, the performance variation was tested with male and female swimmers grouped in the same sample. The analysis of covariance indicated that the maturation stage was a relevant predictor of the $400 \mathrm{~m}$ performance time changes $\left(F_{1.31}=4.67\right.$, $p=0.04$ ) and body mass index changes did not interfere with the $400 \mathrm{~m}$ time at each testing moment $\left(F_{1.31}=0.34, p=0.56\right)$ or in performance changes between testing moments $(p>0.05)$. Young swimmers improved their performance across the year, with the $400 \mathrm{~m}$ front crawl time decreasing from T4 compared to T1 (mean $\pm \mathrm{SD}$, $[95 \% \mathrm{CI}] ; 14.6 \pm 5.9 \%$; 
$12.5,16.7 \% ; F_{3.99}=89.8, p<0.001$, Table 3). Moreover, the $400 \mathrm{~m}$ time decreased after each macrocycle (T2 vs. T1, $7.8 \pm 5.6 \%, 5.8,9.7 \%$; T3 vs. T2, $3.7 \pm 3.1 \% ; 2.6,4.8 \%$, and $\mathrm{T} 4$ vs. $\mathrm{T} 3$, $3.8 \pm 3.4 \% ; 2.6,5.0 \% ; p<0.01$, Table 3). The time in each $100 \mathrm{~m}$ split in the $400 \mathrm{~m}$ effort decreased in each successive test from T1 to T4 (Figure 1).

Table 3. Changes in swimmers' anthropometric, physiological, and biomechanical variables during the four $400 \mathrm{~m}$ front crawl testing moments. Mean $\pm \mathrm{SD}, 95 \%$ confidence intervals $(95 \% \mathrm{CI})$, and effect size (ES) are presented.

\begin{tabular}{|c|c|c|c|c|c|}
\hline Variables & T1 & T2 & T3 & $\mathrm{T} 4$ & $\eta^{2}(p)$ \\
\hline Body mass (kg) & $44.39 \pm 9.33$ & $45.42 \pm 9.22 *$ & $47.00 \pm 9.21{ }^{*}+$ & $47.31 \pm 9.58 *+$ & $0.45(0.00)$ \\
\hline $95 \% \mathrm{CI}$ & $41.14-47.65$ & $42.51-49.20$ & $43.79-50.21$ & $43.96-50.65$ & \\
\hline ES & vs. T2: 0.10 & vs. T3: 0.16 & vs. T4: 0.04 & vs. T1: 0.30 & \\
\hline Height (m) & $1.52 \pm 0.10$ & $1.55 \pm 0.10$ & $1.56 \pm 0.10 *+$ & $1.58 \pm 0.10 *+$ & $0.68(0.00)$ \\
\hline $95 \% \mathrm{CI}$ & $1.49-1.56$ & $1.51-1.59$ & $1.53-1.60$ & $1.54-1.61$ & \\
\hline ES & vs. T2: 0.24 & vs. T3: 0.15 & vs. T4: 0.15 & vs. T1: 0.54 & \\
\hline Body mass index $\left(\mathrm{kg} \cdot \mathrm{m}^{2}\right)$ & $19.05 \pm 2.35$ & $18.99 \pm 2.28$ & $19.11 \pm 2.17$ & $18.88 \pm 2.28$ & $0.03(0.41)$ \\
\hline $95 \% \mathrm{CI}$ & 18.17-19.79 & $18.06-19.70$ & 18.38-19.84 & 18.09-19.64 & \\
\hline ES & vs. T2: -0.07 & vs. T3: 0.11 & vs. T4: -0.10 & vs. T1: -0.07 & \\
\hline Time $400 \mathrm{~m}(\mathrm{~s})$ & $432.37 \pm 71.78$ & $396.58 \pm 55.00 *$ & $381.67 \pm 51.9 *+$ & $366.66 \pm 47.7^{*}+x$ & $0.98(0.00)$ \\
\hline $95 \% \mathrm{CI}$ & $407.33-457.42$ & 377.39-415.76 & 363.57-399.78 & 350.02-383.30 & \\
\hline ES & vs. T2: -0.56 & vs. T3: -0.28 & vs. T4: -0.30 & vs. T1: -1.10 & \\
\hline Heart rate (bpm) & $154.28 \pm 23.92$ & $155.97 \pm 26.62$ & $155.67 \pm 26.08$ & $156.00 \pm 26.67$ & $0.03(0.36)$ \\
\hline $95 \%$ CI & $175.52-186.61$ & 181.17-190.36 & 182.10-189.09 & 180.04-189.96 & \\
\hline ES & vs. T2: 0.23 & vs. T3: -0.01 & vs. T4: -0.05 & vs. T1: 0.16 & \\
\hline Blood lactate $\left(\mathrm{mmol} \cdot \mathrm{L}^{-1}\right)$ & $6.04 \pm 2.33$ & $6.32 \pm 2.51$ & $7.16 \pm 2.67 *$ & $7.94 \pm 2.74 *+$ & $0.21(0.00)$ \\
\hline $95 \% \mathrm{CI}$ & $5.22-6.85$ & $5.44-7.19$ & $6.23-8.10$ & 6.98-8.89 & \\
\hline ES & vs. T2: 0.12 & vs. T3: 0.33 & vs. T4: 0.28 & vs. T1: 0.75 & \\
\hline Blood glucose $\left(\mathrm{mmol} \cdot \mathrm{L}^{-1}\right)$ & $110.30 \pm 15.88$ & $102.29 \pm 19.68$ & $122.88 \pm 18.35^{*}+$ & $118.03 \pm 27.31+$ & $0.26(0.00)$ \\
\hline $95 \% \mathrm{CI}$ & $104.75-115.84$ & $95.43-109.16$ & $116.48-129.29$ & 108.50-127.56 & \\
\hline ES & vs. T2: -0.45 & vs. T3: 1.08 & vs. T4: -0.21 & vs. T1: 0.36 & \\
\hline Rating of perceived exertion & $14.91 \pm 1.93$ & $14.88 \pm 2.40$ & $15.09 \pm 2.19$ & $14.59 \pm 2.44$ & $0.01(0.68)$ \\
\hline $95 \% \mathrm{CI}$ & $14.24-15.58$ & $14.05-15.72$ & $14.32-15.85$ & $13.74-15.44$ & \\
\hline ES & vs. T2: -0.01 & vs. T3: 0.09 & vs. T4: -0.22 & vs. T1: -0.15 & \\
\hline Stroke rate $\left(\right.$ cycles $\cdot \min ^{-1}$ ) & $36.47 \pm 3.83$ & $37.14 \pm 4.96$ & $37.75 \pm 5.19 *$ & $37.63 \pm 4.87$ * & $0.09(0.02)$ \\
\hline $95 \% \mathrm{CI}$ & $35.01-37.69$ & $35.61-38.66$ & $36.00-39.14$ & $36.28-38.97$ & \\
\hline ES & vs. T2: 0.20 & vs. T3: 0.07 & vs. T4: 0.02 & vs. T1: 0.31 & \\
\hline Stroke length $\left(\mathrm{m} \cdot \mathrm{cycle}^{-1}\right)$ & $1.58 \pm 0.24$ & $1.67 \pm 0.20^{*}$ & $1.72 \pm 0.24 *$ & $1.78 \pm 0.22 *+x$ & $0.48(0.00)$ \\
\hline $95 \% \mathrm{CI}$ & $1.49-1.66$ & $1.60-1.74$ & $1.63-1.80$ & $1.70-1.85$ & \\
\hline ES & vs. T2: 0.41 & vs. T3: 0.22 & vs. T4: 0.26 & vs. T1: 0.87 & \\
\hline Stroke index $\left(\mathrm{m}^{2} \cdot \mathrm{s}^{-1} \cdot \mathrm{cycle}^{-1}\right)$ & $1.53 \pm 0.46$ & $1.73 \pm 0.42 *$ & $1.86 \pm 0.48^{*}+$ & $1.99 \pm 0.47^{*}+\mathrm{x}$ & $0.71(0.00)$ \\
\hline $95 \% \mathrm{CI}$ & $1.37-1.69$ & $1.59-1.88$ & $1.69-2.02$ & $1.83-2.16$ & \\
\hline ES & vs. T2: 0.47 & vs. T3: 0.28 & vs. T4: 0.29 & vs. T1: 1.00 & \\
\hline
\end{tabular}

T1: beginning of the general preparation period of the first macrocycle; T2, T3, and T4: end of the competitive period of the first, second, and third macrocycles, respectively. ${ }^{*},+$, and $\mathrm{x}: p<0.05$ compared to $\mathrm{T} 1, \mathrm{~T} 2$, and $\mathrm{T} 3$.

\subsection{Changes in Physiological Variables and Rating of Perceived Exertion Following $400 \mathrm{~m}$}

There was no difference between testing moments in the post- $400 \mathrm{~m} \mathrm{HR}\left(F_{3.99}=1.07\right.$; $p=0.36$, Table 3). Moreover, the HR was decreasing over the recovery period following each $400 \mathrm{~m}$ test (from 10-120 s) without any difference in the rate of recovery between testing moments. Following T3 and T4 testing moments, the post- $400 \mathrm{~m}[\mathrm{La}]$ increased compared to T1 $(p<0.05)$. An increment was also observed after T4 compared to T2 $\left(F_{3.99}=8.5 ; p<0.01\right.$; Table 3). Blood [Glu] increased in T3 compared to T2 and T1 and in T4 compared to T2 $\left(F_{3.99}=11.43 ; p<0.01\right.$, Table 3$)$. There was no difference in the ratings of perceived exertion between the four testing moments $\left(F_{3.99}=0.49 ; p=0.68\right.$, Table 3$)$. 


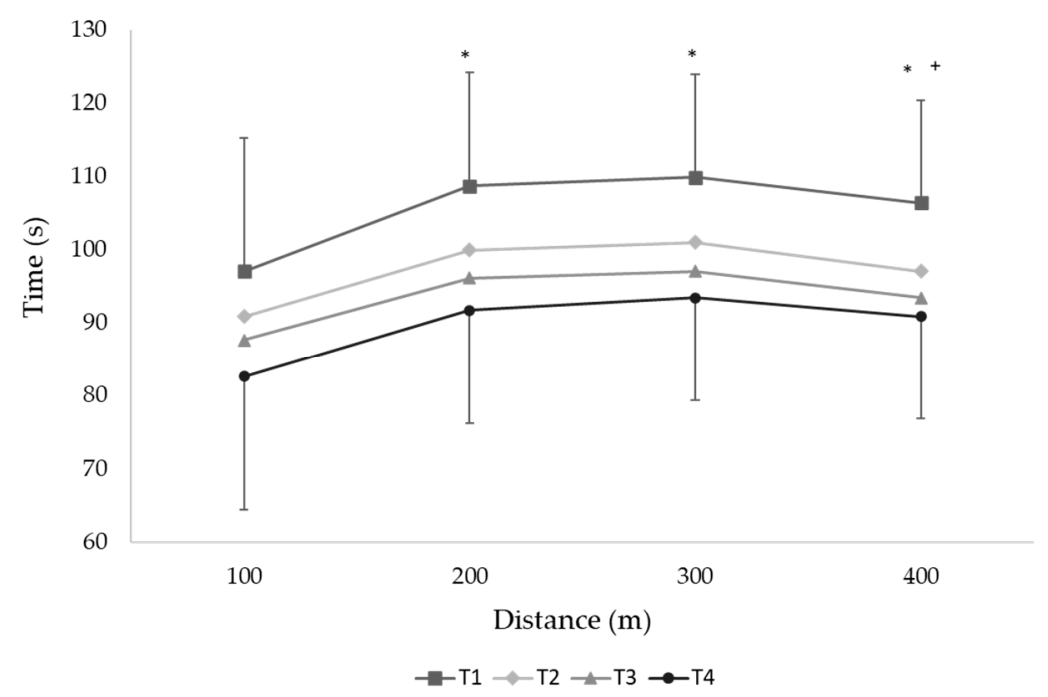

Figure 1. Time for each $100 \mathrm{~m}$ split in the $400 \mathrm{~m}$ front crawl effort at testing moments $\mathrm{T} 1$ (beginning of the first macrocycle) and T2, T3, and T4 (end of the first, second, and third macrocycles, respectively). * and +: $p<0.05$ compared to $100 \mathrm{~m}$ partial and to 200 and $300 \mathrm{~m}$ partials.

\subsection{Changes in Technique and Anthropometry}

The mean SR of the $400 \mathrm{~m}$ front crawl increased at T3 and T4 compared to T1 $\left(F_{3.96}=3.36, p=0.02\right.$, Table 3). This variable decreased in the second, third, and fourth partials compared to the first $100 \mathrm{~m}$ split and increased in the last split independent of the testing moment $\left(F_{3.96}=90.6, p<0.01\right.$, Figure 2$)$. The SL augmented after T2, T3, and T4 compared to T1 and after T4 compared to T2 and T3 $\left(F_{3.99}=31.45, p<0.01\right.$, Table 3$)$. A decreased SL was observed after the second, third, and fourth partials compared to the first $100 \mathrm{~m}$ split $\left(F_{3.99}=20.57, p<0.01\right)$. The SI improved in each testing moment compared to the previous one (T1 vs. T2, T2 vs. T3, and T3 vs. T4, $F_{3.99}=82.44, p<0.01$, Table 3 ) and declined in each $100 \mathrm{~m}$ split compared to the previous one in all testing moments $(p<0.01$, Figure 3).

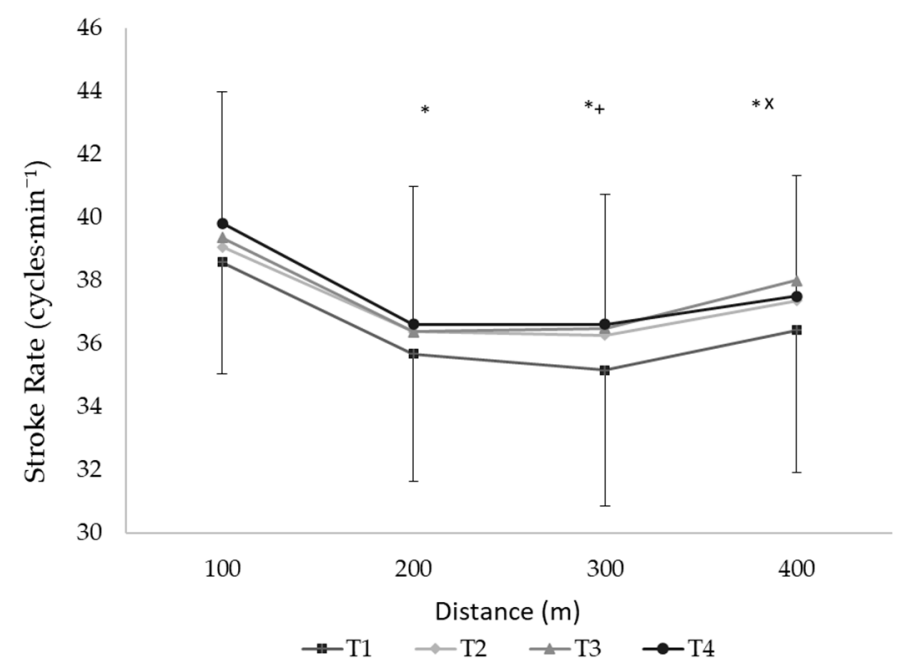

Figure 2. The stroke rate in each $100 \mathrm{~m}$ split of the $400 \mathrm{~m}$ front crawl effort at testing moments $\mathrm{T} 1, \mathrm{~T} 2$, T3, and T4. T1: beginning of the first macrocycle; T2, T3, and T4: end of the first, second, and third macrocycles, respectively. ${ }^{*}$ and $+: p<0.05$ compared to $100 \mathrm{~m}$ and $400 \mathrm{~m} .{ }^{\mathrm{x}}: p<0.05$ compared to 200 m partial. 


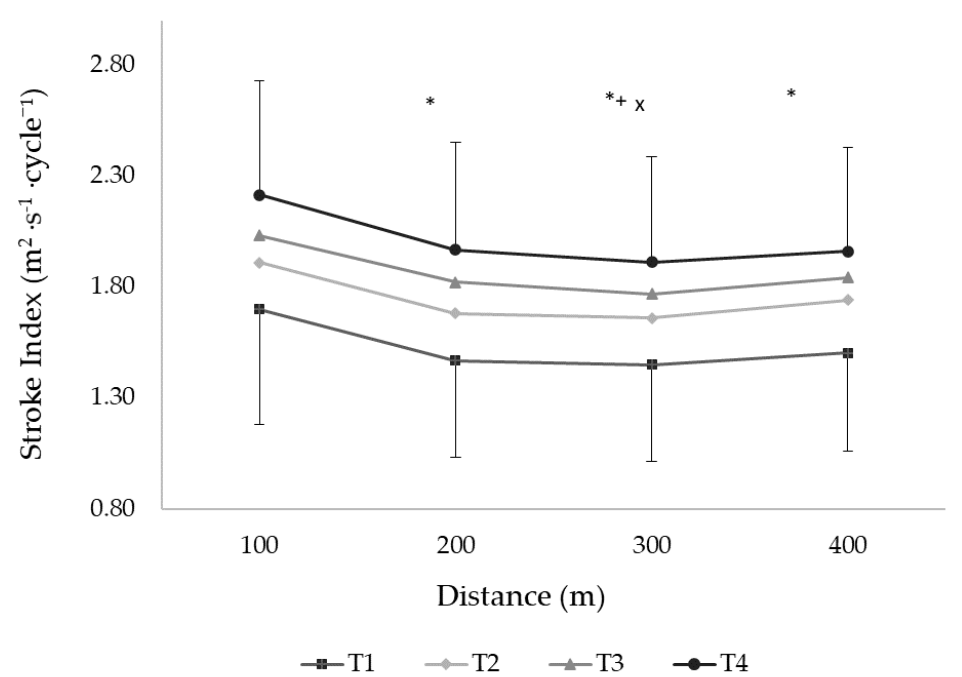

Figure 3. The stroke index in each $100 \mathrm{~m}$ split of the $400 \mathrm{~m}$ front crawl effort at testing moments $\mathrm{T} 1$, T2, T3, and T4. T1: beginning of the first macrocycle; T2, T3, and T4: end of the first, second, and third macrocycles, respectively. ${ }^{*}$ and $+: p<0.05$ compared to $100 \mathrm{~m}$ and $400 \mathrm{~m} .{ }^{\mathrm{x}}: p<0.05$ compared to $200 \mathrm{~m}$ partial.

\subsection{Relationships between Variables}

All the measured variables, at each testing moment, are related $(p<0.05)$ with the 400 m front crawl speed (Table 4).

Table 4. Correlation values between anthropometric, physiological, and biomechanical variables and the $400 \mathrm{~m}$ front crawl performance at the four testing moments of the season.

\begin{tabular}{ccccc}
\hline Variables & T1 & T2 & T3 & T4 \\
\hline Body mass $(\mathrm{kg})$ & $0.35^{*}$ & $0.35^{*}$ & 0.26 & 0.34 \\
Stature $(\mathrm{m})$ & $0.39^{*}$ & $0.40^{*}$ & 0.33 & $0.411^{*}$ \\
Blood lactate $\left(\mathrm{mmol} \cdot \mathrm{L}^{-1}\right)$ & $0.50^{*}$ & $0.72 *$ & $0.62 *$ & $0.55^{*}$ \\
Blood glucose $\left(\mathrm{mmol} \cdot \mathrm{L}^{-1}\right)$ & $0.41^{*}$ & $0.55^{*}$ & $0.54 *$ & $0.50^{*}$ \\
Stroke rate $\left(\mathrm{cycle} \cdot \mathrm{min}^{-1}\right)$ & $0.42^{*}$ & $0.63 *$ & $0.45^{*}$ & $0.52^{*}$ \\
Stroke length $\left(\mathrm{m} \cdot \mathrm{cycle}^{-1}\right)$ & $0.77^{*}$ & $0.59 *$ & $0.63 *$ & $0.67 *$ \\
Stroke index $\left(\mathrm{m}^{2} \cdot \mathrm{s}^{-1} \cdot \mathrm{cycle}^{-1}\right)$ & $0.93 *$ & $0.91 *$ & $0.91 *$ & $0.92^{*}$
\end{tabular}

T1: beginning of the general preparation period of the first macrocycle; T2, T3, and T4: end of the competitive period of the first, second, and third macrocycles. *: $p<0.05$.

Changes in anthropometric variables between macrocycles (such as body mass, stature, and body mass index) were not related to the $400 \mathrm{~m}$ speed changes $(r=-0.05$ to 0.20 , $p>0.05)$. Blood lactate and blood glucose changes from T1 to T2 were related to $400 \mathrm{~m}$ speed changes $(r=0.35$ and $0.36, p<0.05)$, but subsequent changes from T2 to T3, T3 to T4, and T1 to T4 showed no relationship with $400 \mathrm{~m}$ speed modifications $(p>0.05)$. SR changes were not related to speed alterations ( $p>0.05)$, and SL changes from T1 to T2, T3 to T4, and $\mathrm{T} 1$ to $\mathrm{T} 4$ were related to $400 \mathrm{~m}$ speed modifications $(r=60,0.34$, and $0.58, p<0.05)$. The calculated SI is the only measured variable that is significantly related with the increase in speed between all testing moments (Figure 4). 


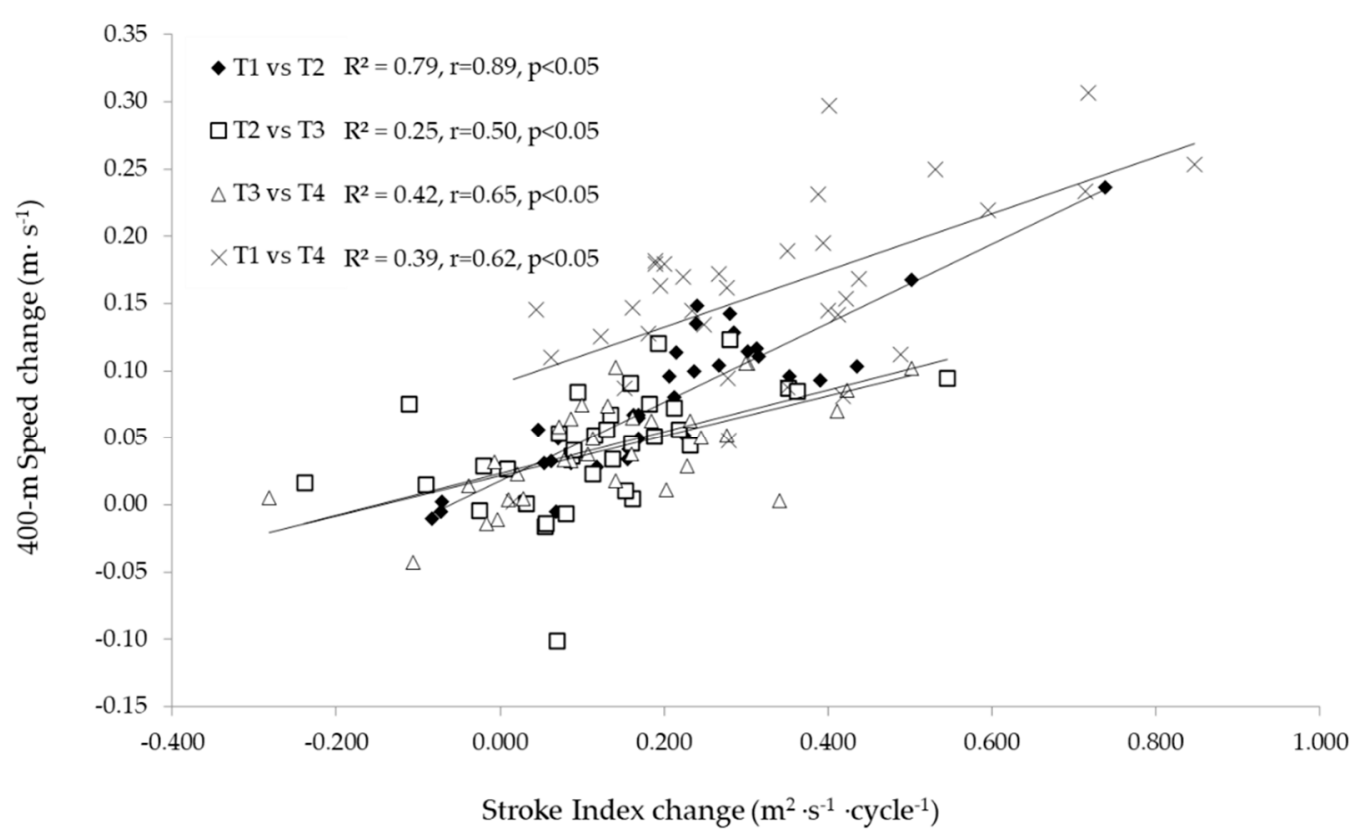

Figure 4. Relationship of stroke index changes and $400 \mathrm{~m}$ speed changes between macrocycles. T1: beginning of the general preparation period of the first macrocycle; T2, T3, and T4: end of the competitive period of the first, second, and third macrocycles.

\section{Discussion}

The purpose of the current study was to follow up on the evolution of young swimmers' middle-distance performance (and respective physiological and biomechanical changes) along a training season. For that purpose, a 45-week longitudinal evaluation was used along the three macrocycles of the year plan and four $400 \mathrm{~m}$ front crawl tests (a distance commonly used in age group training, competition, and monitoring $[4,10,13]$ ) were conducted. It is known that metabolic factors provide the basis for swimming performance improvement, especially in the first macrocycle of the season [3,5,15], and that technique progression is evident along the training season $[2,6,27]$. However, there are very few longitudinal studies available on young swimmers, and they too lack detailed information about the interplay between the changes in performance, its determinant variables, and training contents over a full training swimming season.

We observed that performance increased by $14.6 \%$ along the three macrocycles, with a greater improvement observed in the first, followed by the second and third macrocycles. Previous studies have already reported 1.9-3.6\% improvement in a $400 \mathrm{~m}$ test over a training season in young male and female swimmers $[13,28]$. In the current study, most of the anthropometric and biomechanical variables were substantially improved, especially during the first macrocycle, with $\sim 2$ and $12 \%$ stature and SI improvements observed from T1 to T2 (consisting in half of their overall improvement within the 45 weeks). Since it is well accepted that different factors contribute to young swimmers' performance enhancement $[6,16,27]$, the observed $400 \mathrm{~m}$ time improvements may also be related to training content and corresponding metabolic changes within each macrocycle. In fact, increased training intensity (through higher anaerobic loads) may alter swimming performance improvement rate $[10,17,29]$. As such, the $\sim 12$ and $18 \%$ rise in [La] and [Glu], despite an attenuated improvement in SI and SL during T3 compared to T2, may explain the differences in the observed performance improvement rates, in agreement with a previous study [8].

The current study relationships between the anthropometric, physiological, and biomechanical variables and the $400 \mathrm{~m}$ front crawl time confirmed their importance for young swimmers' middle-distance performance (as observed before $[8,10,28]$ ). However, even if most of the measured variables correlated well with the $400 \mathrm{~m}$ performance, its magnitude 
altered between testing moments. Body mass and stature, in agreement with previous studies $[13,17,28]$, were moderately related with performance during T1 and T2, a period where the greater improvement in these variables was observed in the current study. In addition, SL and SI displayed consistent high correlation values with middle-distance swimming, highlighting its importance for swimmers in this age group (as proposed before $[5,8,15])$. [La] and [Glu] variables were also well related with the $400 \mathrm{~m}$ speed along all the testing moments, supporting the idea that energetics and technique have a relative higher contribution to aerobic power efforts compared to body mass and stature $[8,10,17]$. Any differences between the magnitudes of the correlation values in the current data and the literature may be attributed to the distance selected as a performance criterion (i.e., 100, 200 , vs. $400 \mathrm{~m}$ ), the swimmer's age, and the year training period $[4,10,15]$.

All variables' modifications were also examined in relation to the $400 \mathrm{~m}$ front crawl speed changes over the training period. SI variations were strongly related to $400 \mathrm{~m}$ speed increments between testing moments. This was not a surprise since it is known that the SI discriminates the swimmers' technical ability $[6,18,19]$, which is likely more important for longer than shorter distances $[8,15,20]$. The SI increased by 23\% from T1 to T4, with the greater improvement observed between $\mathrm{T} 1$ and $\mathrm{T} 2$ (as expected for the initial training macrocycle). Similar findings were reported before, recognizing SI as a factor explaining $90 \%$ of the swimming performance in distances of 100-400 $\mathrm{m}$ [14], which may be connected to technical improvements or increments in body dimensions [6]. A significant technique training content in the first macrocycle may have contributed to the greater improvement between $\mathrm{T} 1$ and $\mathrm{T} 2$ moments.

[La] values increased along the training season, possibly due to the anaerobic training content increment between macrocycles that led to a higher glycolytic contribution to the $400 \mathrm{~m}$ front crawl performances [8,22]. It should be noted that [La] variations between T1 and T2 were related to $400 \mathrm{~m}$ performance changes, a fact that was not observed in the second and third macrocycles. It is likely that increased training intensity led to metabolic changes within a macrocycle (12-18 weeks), which affected performance [8,29], even if the technical training contributes more than $50 \%$ to performance improvement [8]. It seems that our younger swimmers' technique changes were more evident than those reported in adolescent swimmers [8], a fact supported by the continuous importance of SI and SL changes in all testing moments.

[Glu] values were higher at T3 and T4 compared to T2. A previous work showed that [La] and [Glu] increases are coincident [17], and another study stated that [Glu] alone may not be adequate to express training-induced improvements [30]. In the current study, [Glu] modifications were related to $400 \mathrm{~m}$ performance changes in a manner similar to [La] changes (presenting similar correlation values), which may indicate a metabolic connection among these metabolites. Although the current swimmers' diet and training were controlled, a complex metabolic mechanism is connected to [Glu] regulation, making it difficult to explain the changes in this variable. In addition, post-swim [Glu] levels may be altered by the intensity and/or the duration of the swimming bouts [31]. Whatever the case, the significant [Glu] connection with performance changes between T1 and T2 indicates its importance, requiring a more in-depth evaluation in future studies.

\section{Conclusions}

The current study findings indicate that a well-designed year plan, with the training periods coinciding with the swimmers' school calendar, leads to a significant middledistance swimming performance improvement in young swimmers. The fact that the $400 \mathrm{~m}$ front crawl speed enhancement along the season is mostly connected with an increase in the values of biomechanical (SL and SI) variables suggests that when swimmers are in this age group, coaches should prioritize the swimmers' technique development. It should be highlighted that, concomitantly with perfection in swimming skills, physiological variables (such as [Glu] and [La]) are likely important to optimize middle-distance swimming performance. Thus, coaches may combine a robust technical training in the beginning of 
the season with a progressive increase in training intensity across macrocycles (aiming to gradually stimulate the anaerobic metabolism) for optimal performance progression in young swimmers. In female swimmers, the phase of the menstrual cycle was not controlled, which can affect fluid retention and performance. Since this is a factor that potentially adds variability in the data, future studies should consider this issue.

Author Contributions: Conceptualization, S.F., D.D.C., A.T., and R.J.F.; methodology, S.F., D.D.C., S.S., A.T., and R.J.F.; formal analysis, S.F. and D.D.C.; investigation, S.F., D.D.C., R.C., and M.R.; resources, R.J.F.; writing—original draft preparation, S.F, D.D.C., and R.C.; writing—review and editing, S.F., D.D.C., R.C., M.R., S.S., A.T., and R.J.F.; visualization, S.F. and D.D.C.; supervision, A.T. and R.J.F.; project administration, S.F., D.D.C., and R.J.F. All authors have read and agreed to the published version of the manuscript.

Funding: This research received no external funding

Institutional Review Board Statement: The study was conducted according to the guidelines of the Declaration of Helsinki and approved by the Institutional Review Board (or Ethics Committee) of the Faculty of Sport of the University of Porto (CEFADE 04-2017).

Informed Consent Statement: Informed consent was obtained from all subjects involved in the study.

Data Availability Statement: Data presented in this study are available on request from the corresponding author. The data are not publicly available due to ethical reasons.

Acknowledgments: We acknowledge the participation of the coaches and swimmers.

Conflicts of Interest: The authors declare no conflict of interest.

\section{References}

1. Kojima, K.; Jamison, P.; Stager, J. Multi-age-grouping paradigm for young swimmers. J. Sports Sci. 2012, 30, 313-320. [CrossRef]

2. Silva, A.; Figueiredo, P.; Soares, S.; Seifert, L.; Vilas-Boas, J.P.; Fernandes, R.J. Front crawl technical characterization of 11-13 years old swimmers. Pediatric Exerc. Sci. 2012, 24, 409-419. [CrossRef] [PubMed]

3. Tucher, G.; Castro, F.A.S.; Garrido, N.D.; Fernandes, R.J. Monitoring changes over a training macrocycle in regional age-group swimmers. J. Hum. Kinet. 2019, 69, 213-223. [CrossRef] [PubMed]

4. Bielec, G.; Makar, P.; Fernandes, R.J. The influence of short-term training volume increase on biomechanical variables in age-group swimmers. J. Phys. Educ. Sport 2020, 20, 2539-2544. [CrossRef]

5. Fernandes, R.; Sousa, M.; Pinheiro, A.; Vilar, S.; Colaco, P.; Vilas-Boas, J.P. Assesment of individual anaerobic threshold and stroking parameters in swimmers aged 10-11 years. Eur. J. Sports Sci. 2010, 10, 311-317. [CrossRef]

6. Barbosa, T.; Bartolomeu, R.; Morais, J.; Costa, M. Skillful swimming in age-groups is determined by anthropometrics, biomechanics and energetics. Front. Physiol. 2019, 10, 73. [CrossRef]

7. Issurin, V.B. New horizons for the methodology and physiology of training periodization. Sports Med. 2010, 40, 189-206. [CrossRef]

8. Zacca, R.; Azevedo, R.; Ramos, V.R.; Abraldes, J.A.; Vilas-Boas, J.P.; Castro, F.A.S.; Pyne, D.B.; Fernandes, R.J. Biophysical follow-up of age-group swimmers during a traditional three-peak preparation program. J. Strength Cond. Res. 2020, 34, 2585-2595. [CrossRef]

9. Mujica, I.; Chatard, J.C.; Busso, T.; Geyssant, A.; Barale, F.; Lacoste, L. Effects of training on performance in competitive swimmers. Can. J. Appl. Physiol. 1995, 20, 395-406. [CrossRef]

10. Zacca, R.; Azevedo, R.; Chainok, P.; Vilas-Boas, J.-P.; Castro, F.A.S.; Pyne, D.B.; Fernandes, R.J. Monitoring age-group swimmers over a training macrocycle: Energetic, technique, and anthropometrics. J. Strength Cond. Res. 2020, 34, 818-827. [CrossRef]

11. Bompa, T.O. Periodization Training: Theory and Methodology, 4th ed.; Human Kinetics Publishers: Champaign, IL, USA, 1999.

12. Obert, P.; Mandigout, S.; Vinet, A.; N' Guyen, L.D.; Stecken, F; Courteix, D. Effect of aerobic training and detraining on left ventricular dimensions and diastolic function in prepubertal boys and girls. Int. J. Sports Med. 2001, 22, 90-96. [CrossRef] [PubMed]

13. Lätt, E.; Jürimäe, J.; Haljaste, K.; Cicchella, A.; Purge, P.; Jürimäe, T. Longitudinal development of physical and performance parameters during biological maturation of young male swimmers. Percept. Mot. Ski. 2009, 108, 297-307. [CrossRef] [PubMed]

14. Mezzaroba, P.V.; Machado, F.A. Effect of age, anthropometry, and distance in stroke parameters of young swimmers. Int. J. Sports Phys. Perform. 2014, 9, 702-706. [CrossRef] [PubMed]

15. Morais, J.E.; Saavedra, J.M.; Costa, M.J.; Silva, A.J.; Marinho, D.A.; Barbosa, T.M. Tracking young talented swimmers: Follow-up of performance and its biomechanical determinant factors. Acta Bioeng. Biomech. 2013, 15, 129-138. [PubMed] 
16. Figueiredo, P.; Silva, A.; Sampaio, A.; Vilas-Boas, J.P.; Fernandes, R.J. Front crawl sprint performance: A cluster analysis of biomechanics, energetics, coordinative, and anthropometric determinants in young swimmers. Mot. Control 2016, 20, 209-221. [CrossRef]

17. Ferreira, S.; Carvalho, D.; Monteiro, A.S.; Abraldes, J.; Vilas-Boas, J.P.; Toubekis, A.; Fernandes, R. Physiological and Biomechanical Evaluation of training macrocycle in children swimmers. Sports 2019, 7, 57. [CrossRef]

18. Fernandes, R.J.; Marinho, D.A.; Barbosa, T.; Vilas-Boas, J.P. Is time limit at the minimum swimming velocity of $\mathrm{VO}_{2} \mathrm{max}$ influenced by stroking parameters? Percept. Mot. Ski. 2006, 103, 67-75. [CrossRef]

19. Marinho, D.A.; Vilas-Boas, J.P.; Keskinen, K.L.; Rodríguez, F.A.; Soares, S.M.; Carmo, C.M.; Vilar, S.O.; Fernandes, R.J. The behaviour of the kinematic parameters during a time to exhaustion test at VO2max in elite swimmers. J. Hum. Mov. Stud. 2006, $51,1-10$

20. Pelarigo, J.; Grecco, C.C.; Denadai, B.S.; Fernandes, R.J.; Vilas-Boas, J.P.; Pendergast, D.R. Do 5\% changes around maximal lactate steady state lead to swimming biophysical modifications? Hum. Mov. Sci. 2016, 49, 258-266. [CrossRef]

21. Silveira, R.P.; Soares, S.M.; Zacca, R.; Alves, F.B.; Fernandes, R.J.; Castro, F.A.S.; Vilas-Boas, J.P. A biophysical analysis on the arm stroke efficiency in front crawl swimming: Comparing methods and determining the main performance predictors. Int. J. Environ. Res. Public Health 2019, 16, 4715. [CrossRef]

22. Piatrikova, E.; Sousa, A.C.; Willsmer, N.J.; Gonzalez, J.T.; Williams, S. Demarcating Exercise Intensity Domains in Freestyle Swimming: Is There an Alternative to Incremental Step Test and Beats Below HRmax Method? J. Strength Cond. Res. 2020, 34, 2575-2584. [CrossRef] [PubMed]

23. Reis, J.F.; Matias, C.N.; Campa, F.; Morgado, J.P.; Franco, P.; Quaresma, P.; Almeida, N.; Curto, D.; Toselli, S.; Monteiro, C.P. Bioimpedance vector patterns changes in response to swimming training: An ecological approach. Int. J. Environ. Res. Public Health 2002, 17, 4851. [CrossRef] [PubMed]

24. Carvalho, D.D.; Soares, S.; Zacca, R.; Marinho, D.A.; Silva, A.J.; Pyne, D.B.; Vilas-Boas, J.P.; Fernandes, R.J. In-Water and On-Land Swimmers' Symmetry and Force Production. Int. J. Environ. Res. Public Health 2019, 16, 5018. [CrossRef] [PubMed]

25. Tanner, J.M.; Whitehouse, R.H. Atlas of Children's Growth Normal Variation and Growth Disorders; Academic Press: London, UK, 1982.

26. Cohen, J. Statistical power analysis. Curr. Dir. Psychol. Sci. 1992, 1, 98-101. [CrossRef]

27. Morais, J.E.; Marques, M.C.; Marinho, D.A.; Seifert, L.; Barbosa, T.M. Longitudinal modeling in sports: Young swimmer's performance and biomechanics profile. Hum. Mov. Sci. 2014, 37, 111-122. [CrossRef]

28. Lätt, E.; Jurimäe, J.; Haljaste, K.; Cicchella, A.; Purge, P.; Jurimäe, T. Physical development and swimming performance during biological maturation in young female swimmers. Coll. Antropol. 2009, 33, 117-122. [PubMed]

29. Toubekis, A.; Tsami, A.P.; Smilios, I.; Douda, H.; Tokmakidis, S. Training induced changes on blood lactate profile and critical velocity in young swimmers. J. Strength Cond. Res. 2011, 25, 1563-1570. [CrossRef]

30. Sengoku, Y.; Nakamura, K.; Takeda, T.; Nabekura, Y.; Tsubakimoto, S. Glucose response after a ten-week training in swimming. Int. J. Sports Med. 2011, 32, 835-838. [CrossRef]

31. Kabasakalis, A.; Nikolaidis, S.; Tsalis, G.; Mougios, V. Low-volume sprint interval swimming is sufficient to increase blood metabolic biomarkers in master swimmers. Res. Q. Exerc. Sport 2020. [CrossRef] 